OPEN

SUBJECT AREAS:

BIOLOGICAL

TECHNIQUES

ICHTHYOLOGY

SUSTAINABILITY

Received

10 April 2014

Accepted

11 November 2014

Published

28 November 2014

Correspondence and requests for materials should be addressed to D.V.F. (david.

fairclough@fish.wa. gov.au)

\section{Breathing life into fisheries stock assessments with citizen science}

\author{
D. V. Fairclough, J. I. Brown, B. J. Carlish, B. M. Crisafulli \& I. S. Keay
}

Western Australian Fisheries and Marine Research Laboratories, Department of Fisheries, Government of Western Australia, P.O. Box 20, North Beach, Western Australia 6920, Australia.

Citizen science offers a potentially cost-effective way for researchers to obtain large data sets over large spatial scales. However, it is not used widely to support biological data collection for fisheries stock assessments. Overfishing of demersal fishes along $1,000 \mathrm{~km}$ of the west Australian coast led to restrictive management to recover stocks. This diminished opportunities for scientists to cost-effectively monitor stock recovery via fishery-dependent sampling, particularly of the recreational fishing sector. As

fishery-independent methods would be too expensive and logistically-challenging to implement, a citizen science program, Send us your skeletons (SUYS), was developed. SUYS asks recreational fishers to voluntarily donate fish skeletons of important species from their catch to allow biological data extraction by scientists to produce age structures and conduct stock assessment analyses. During SUYS, recreational fisher involvement, sample sizes and spatial and temporal coverage of samples have dramatically increased, while the collection cost per skeleton has declined substantially. SUYS is ensuring sampling objectives for stock assessments are achieved via fishery-dependent collection and reliable and timely scientific advice can be provided to managers. The program is also encouraging public ownership through involvement in the monitoring process, which can lead to greater acceptance of management decisions.

c

itizen science programs range in the level of responsibility that members of the public have, from those where scientists are contracted to conduct work on the public's behalf, to those where members of the public independently conduct all aspects of the program, including design, implementation, analysis and reporting ${ }^{1}$. However, programs that enlist members of the public as volunteer data collectors (contributory citizen science programs) are perhaps the most common ${ }^{1}$. Such programs have been increasingly employed in recent years for monitoring organisms and environments, both terrestrial and aquatic, e.g. for the collection of presence/ absence data for plants or animals ${ }^{2-6}$. These projects are usually aimed at attracting a large voluntary workforce, which can allow the collection of considerable data sets with substantial spatial and/or temporal coverage that would not be feasible for a research organisation without significant $\operatorname{cost}^{7,8}$. A greater quantity of data may increase statistical precision and power in analyses, but there may also be sampling effects that may influence the quality of the data and require investigation, e.g. volunteer's species identification skills and unbalanced sampling effort ${ }^{5,6,9}$. There are also costs of implementation and maintenance of citizen science programs, e.g. volunteer training, provision of feedback and data analysis. However, they can have long-term cost-effectiveness and lead to benefits that include improved public ownership of a resource and greater acceptance of science and management decisions $\mathrm{s}^{2-4,10}$.

Aquatic citizen science programs are becoming more numerous and include the monitoring of fish species presence/absence and coral health (e.g. www.reef.org; www.redmap.org.au) ${ }^{11,12}$. Recreational fishers have also contributed voluntarily to scientific data collection via catch and effort logbooks and surveys and both contributory and collegial fish-tagging studies, e.g. http://info-fish.net/westag ${ }^{13-18}$. In contrast, the collection of representative biological data necessary for age-based fisheries stock assessments is usually conducted by scientists, rather than citizens, via spatially- and temporally-stratified sampling of catches obtained by fishery-dependent means, e.g. participating commercial fishers' vessels, commercial fish markets and boat-ramp surveys of recreational fishers' catch, and/or by fishery-independent means, e.g. aboard research vessels ${ }^{19-26}$. Other than market sampling of commercial catches, the above approaches are usually expensive, particularly when sampling is required over several years and across a large geographical area. Ways to reduce field costs have included "self-sampling", where a small number of commercial and/or recreational fishers are recruited to donate samples from their catch, usually with instructions on how to select samples, or by requesting recreational fishers to voluntarily donate samples from their catch to supplement active boat-ramp sampling ${ }^{27-31}$. 
Fisheries-dependent and -independent methods for sampling fish populations can result in different characteristics in the collected data set, due to the way that each method selects samples from a population $^{32-34}$. For example, sampling fish length or age data from the catch of recreational fishers, who often preferentially retain larger "trophy" fish, may result in a total sample that is not representative of the overall population. This could influence derived population parameters and requires evaluation ${ }^{13}$. While this does not prevent the use of such data, for scientists to not have control over the selection of samples may have contributed to the limited adoption of large-scale citizen science frameworks for recreational fishers to provide biological samples voluntarily. This is despite the potential advantage of reducing collection costs, while achieving required sample size and spatio-temporal representativeness goals. However, with limited budgets, resource management agencies and scientific organisations need to consider all options ${ }^{8}$.

Snapper Chrysophrys auratus, West Australian dhufish Glaucosoma hebraicum and Baldchin groper Choerodon rubescens are important commercial and recreational fish species along about $1,000 \mathrm{~km}$ of the west coast of Australia (the West Coast Bioregion, WCB). Together they represent the top three demersal species in the annual catch of the boat-based recreational fishery and the first, second and fifth most important species, respectively, in the catch of the commercial line fishery. They also comprise about $70 \%$ of the annual wholesale value of that commercial fishery in the WCB of just below $\$ 4 \mathrm{~m}^{18,35}$. These highly sought-after species hold significant social value, which results in considerable political debate around their management ${ }^{36}$. In 2007, a stock assessment of the three species investigated all available data to determine the status of the stocks, including fishery-dependent age structures and trends in catches, effort and catch rates ${ }^{37}$. Biological data were collected between 2002/03 and 2005/06 by active fisherydependent sampling of commercial catches at fish markets and of recreational catches at fishing competitions and also by self-sampling by a small number of enlisted recreational fishers. Catch and effort data were not of sufficient quality to be able to develop indices of abundance (e.g. standardised catch rates) to combine with age composition data in complex integrated stock assessment models that estimate the biomass of stocks. Thus, fishing mortality rates $(F)$ were estimated from the age compositions of the catch of each species collected from each of the commercial and recreational samples. A range of catch curve methods were used to derive estimates of $F$, which were compared with internationally-accepted biological reference points as the primary method for determining stock status ${ }^{38,39}$.

The 2007 assessment detected that overfishing (high fishing mortality rates) had been occurring of each species ${ }^{37}$. As a result, significant changes were made between late 2007 and early 2010 to the management of both commercial and recreational fishing for these and all other similarly vulnerable demersal fishes in the WCB. The changes were designed to heavily reduce the effect of fishing on stocks (i.e. high $F$ ) via reductions in catch to no more than $50 \%$ of 2005/06 levels (Fig. 1). Changes to commercial fishery management included the commencement of a limited-entry fishery, with each permit-holder entitled a maximum number of hours they could fish per year, and the closure to commercial line fishing of the Metropolitan Area, representing about $20 \%$ of the area of the WCB. Changes to regulations for recreational fishing included, among others, reduced daily bag limits, an annual two month closure to fishing for demersal species in the WCB and the introduction of a recreational fishing from boat licence (Fig. 1) ${ }^{40}$.

The significant management changes achieved the objective of substantially reducing catches ${ }^{41}$, but this negatively and paradoxically affected the ability to obtain age structure data from fisherydependent sources that are required to monitor the recovery of these species. For example, the closure to commercial fishing for demersal species in the Metropolitan Area now means total reliance on recreational fishers in that area for samples. Stratified fishery-independent sampling, commercial vessel surveys and/or large-scale boat-ramp sampling of recreational fishers' catch, either within the Metropolitan Area, or as an alternative for sampling the whole $\mathrm{WCB}$, are extremely labour-intensive and are not possible within current budgets. Thus, ongoing stock assessments based on estimation of $F$ for West Australian dhufish, Snapper and Baldchin groper require the collection of fishery-dependent age structure data from both the commercial and recreational sectors in the four management areas of the WCB, if possible, depending on the areas in which they operate and where each species is important in catches

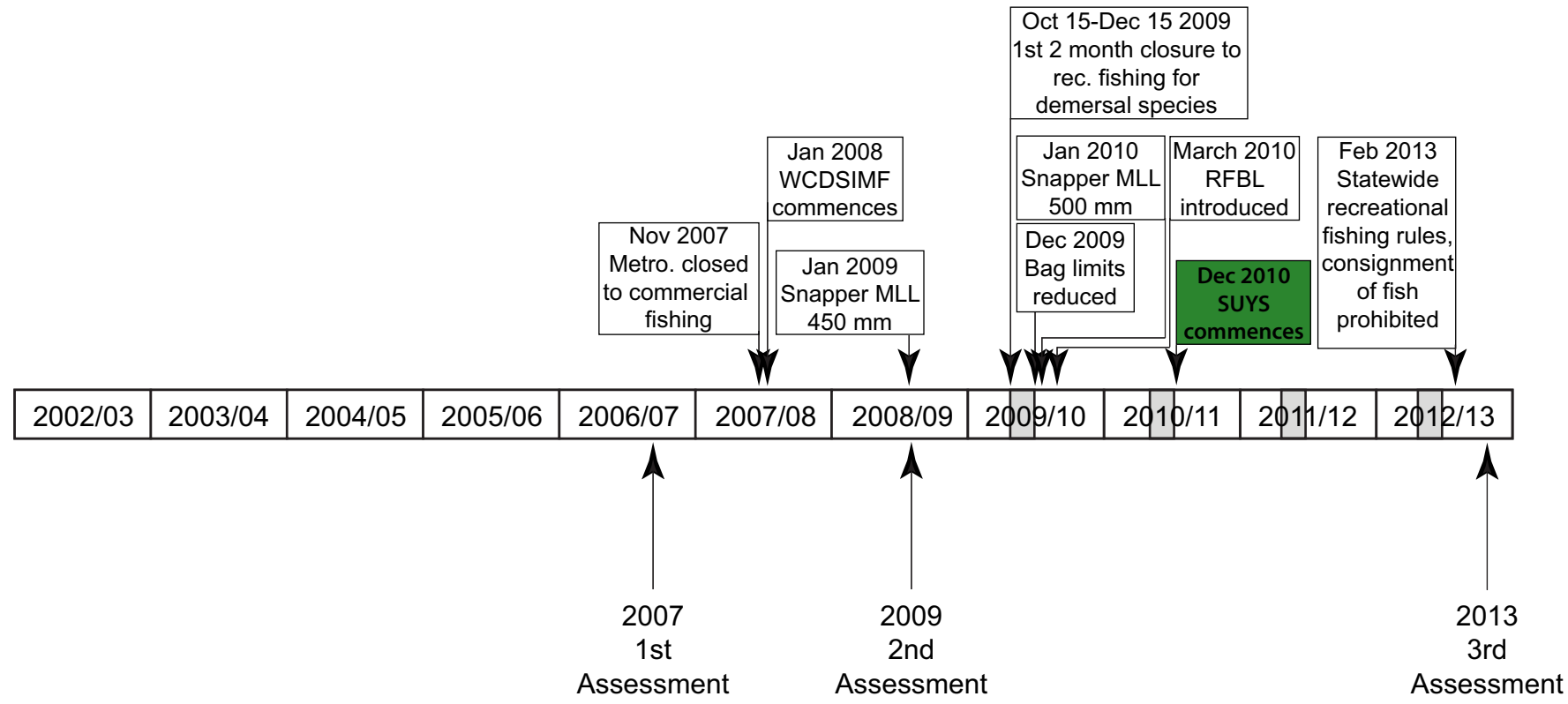

Figure 1 Timeline of assessments and management changes for demersal species in the West Coast Bioregion. Timeline of fish skeleton sampling, assessments, management changes and the commencement of Send Us Your Skeletons (SUYS) for monitoring the key demersal species. WCDSIMF, the commercial West Coast Demersal Scalefish (Interim) Managed Fishery; MLL, minimum legal length; RFBL, Recreational Fishing from a Boat License. Light grey bars represent the timing of the annual two month closure $\left(15^{\text {th }}\right.$ October to $15^{\text {th }}$ December $)$ to recreational fishing for demersal species. 
Table 1 Management areas and sectors ( $C$, commercial; $R$, recreational) in which the key species, West Australian dhufish, Snapper and Baldchin groper, are important in catches and stocks are assessed. 'The Kalbarri Area lies to the north of the Mid-west Area, but is not shown in Figure 4

\begin{tabular}{lllllllll} 
& \multicolumn{2}{c}{ Kalbarri $^{\circ}$} & \multicolumn{2}{c}{ Mid-west } & \multicolumn{2}{c}{ Metropolitan } & \multicolumn{2}{c}{ South-west } \\
\cline { 2 - 9 } Species & $\mathrm{C}$ & $\mathrm{R}$ & $\mathrm{C}$ & $\mathrm{R}$ & $\mathrm{C}$ & $\mathrm{R}$ & $\mathrm{C}$ & $\mathrm{R}$ \\
\hline $\begin{array}{l}\text { West Australian dhufish } \\
\text { Snapper }\end{array}$ & & & $\checkmark$ & $\checkmark$ & & $\checkmark$ & $\checkmark$ & $\checkmark$ \\
Baldchin groper & $\checkmark$ & & $\checkmark$ & $\checkmark$ & & $\checkmark$ & $\checkmark$ & $\checkmark$ \\
\hline
\end{tabular}

$(\text { Table } 1)^{41}$. The complementary data sets provide the necessary geographic coverage of the WCB to assess $F$ separately for each species from each of the commercial and recreational samples and allow comparison of results from the two sampling approaches ${ }^{37,41}$. More complex integrated assessments of biomass will not be possible until a sufficient time series of data on relative abundance of the stocks become available. To achieve sampling objectives and produce robust assessments in a cost-effective manner, the decision was made to (1) continue sampling of commercial fish markets, as this is relatively inexpensive and (2) test the use of a large-scale citizen science program to overcome the issues associated with sampling recreational catches since management changes took effect.

The citizen science program, Send us your skeletons (SUYS), began in 2010/11 (Fig. 1) and asked recreational fishers across the WCB to donate fish skeletons (remains of fish after fillets have been removed) to the Department of Fisheries Western Australia, along with details of their date and location of capture. This study reports the benefits and economic costs of the introduction of SUYS to support ongoing fisheries stock assessments and therefore assess its long-term viability. We tested (1) whether SUYS has successfully attracted and retained greater involvement of the recreational fishing public than prior to the program commencing, (2) whether sample sizes and representativeness of samples from recreational fishers (spatial and temporal coverage) have improved since previous assessments, (3) whether SUYS can be considered to be cost-effective and (4) what the social impact of the program has been via an online survey, i.e. is there awareness and support for the program in the recreational fishing community?

\section{Results}

Fish skeleton numbers. The total number of fish skeletons (fish after fillets have been removed) collected from recreational fishers per year has increased substantially since 2002/03 (Fig. 2a). In 2007/08, accompanied by limited promotion, at least $58 \%$ more skeletons were obtained than in previous years. But, by 2009/10, when the majority of management changes had been introduced and thus catches had been reduced by at least $50 \%$ of those in 2005/06, decreases in the number of fish skeletons obtained from recreational fishers of $5-50 \%$ occurred among management areas, driven by declines in donations of West Australian dhufish (36\%) and Snapper (20\%) in comparison to 2007/08 (Fig. 2a, b). However, after SUYS commenced in late 2010, 69-107\% more skeletons were obtained from recreational fishers per year in each area and of each species than in 2009/10 (Fig. 2a, b). Note that monitoring of Baldchin groper only commenced in 2007/08 and the Kalbarri Area is monitored mainly through commercial sampling (Table 1), with only a small number of recreational fish skeletons donated.

Sources of skeletons and number and fidelity of donors. Prior to $2006 / 07,24-52 \%$ of the total number of skeletons collected from recreational fishers each year was obtained from those who selfsampled and donated the skeletons, with the remainder and typically the majority obtained actively at fishing club events or fishing competitions. In comparison, after SUYS commenced in
2010/11, $\geq 94 \%$ of skeletons were donated voluntarily each year and $\leq 6 \%$ were obtained at competitions and clubs (Fig. 2c).

The number of recreational fishers donating skeletons each year was relatively low $(<50)$ prior to $2007 / 08$ and only $25-44 \%$ of fishers donated skeletons in consecutive years since 2004/05 (Fig. 2d). By $2008 / 09$, following ad hoc promotion, the number of donors more than doubled and after SUYS commenced in 2010/11, the number of donors in that year (355) almost doubled again from 180 in 2009/10 and then increased further by 2012/13 (Fig. 2d). However, only about $30-35 \%$ of fishers have donated skeletons in consecutive years after 2010/11, reflecting the loss of existing donors from the program and recruitment of new donors (Fig. 2d). Although there has been a substantial increase in involvement over time, most fishers have donated only one or two skeletons in total between 2010/11 and $2012 / 13$, with only $5 \%$ donating 20 or more skeletons in those three years (Fig. 2e).

Representativeness of samples and number of sampling events. In $2011 / 12$, the total sample of the three key species represented $6.4 \%$ of the total estimated catch of those species in the WCB in that year, a substantial increase from the $0.8 \%$ sampled in 2005/06 (2005/06 and 2011/12 represent years for which recreational catch estimates were available $^{18,42}$ ). Similarly, the sample size of West Australian dhufish, Snapper and Baldchin groper from 2005/06 and 2011/12 increased from 1.1 to $7.8 \%, 0.8$ to $5.2 \%$ and 0 to $5.9 \%$ of the total catch, respectively, although monitoring of the latter species only commenced in 2007/08.

In line with the increase in skeleton donation and fisher involvement, the total number of sampling events (an event represents a sample of one or more fish donated by a fisher on a single day), increased from less than 200 per year prior to $2007 / 08$ to 900 by 2012/13 (Fig. 2f). Furthermore, the number of sampling events in $2012 / 13$ was more than double that in 2009/10, just prior to SUYS commencing and when management changes had substantially reduced catches.

An example of temporal and spatial coverage. When West Australian dhufish were obtained in the Metropolitan Area during 2004/05, they were typically associated with a small number of sporadic sampling events, resulting in temporal clumping of samples (Fig. 3). In contrast, in 2012/13, after SUYS had commenced, the larger samples of West Australian dhufish were coupled with a greater number of sampling events than in 2004/05 (Fig. 3). Furthermore, sampling events occurred more frequently throughout the year, except for the period of closure to recreational fishing for demersal species (October 15-December 15). Note that a small number of samples were incorrectly dated by fishers as being from that time period.

Since 2002/03, the general location of capture of West Australian dhufish, such as the nearest port, town or oceanic location, was collected for $\geq 93 \%$ of donated fish skeletons. Although samples of West Australian dhufish with a reasonable geographical spread across the WCB were obtained in 2004/05, samples in each management area generally originated from a relatively small number of locations, i.e. 24 (Fig. 4a). In 2012/13, samples of West Australian dhufish originated from approximately double the number of general 
(a)

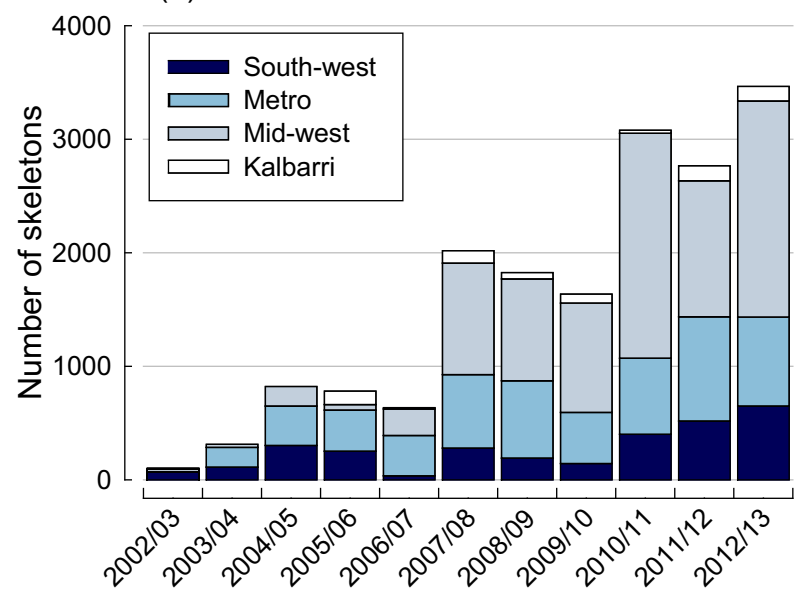

(c)

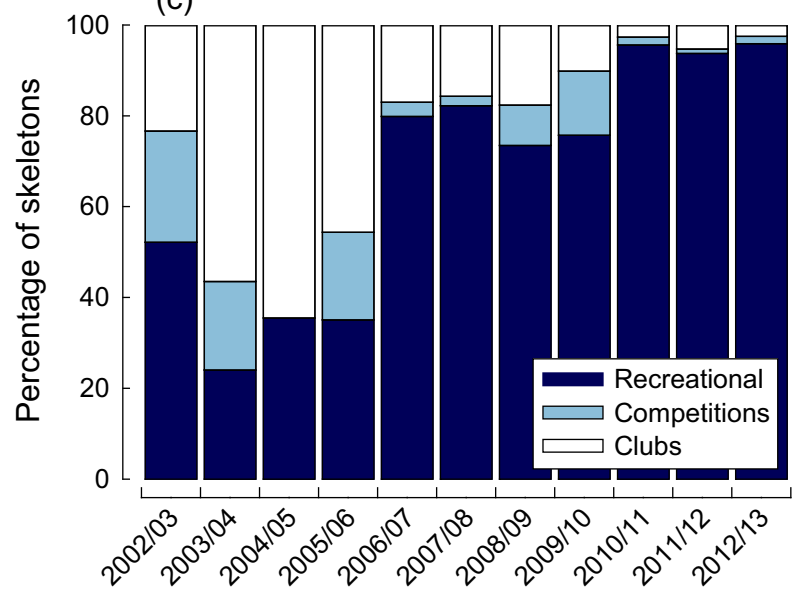

(e)

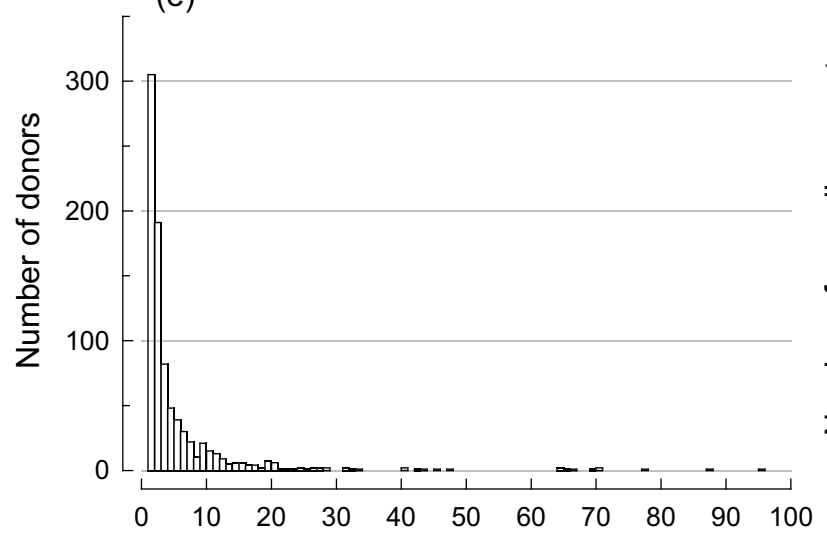

Number of skeletons (b)

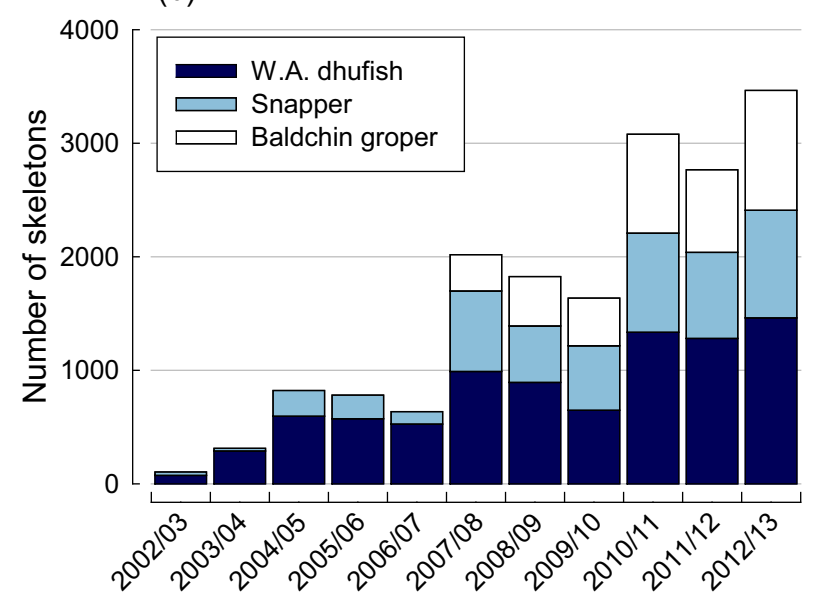

(d)
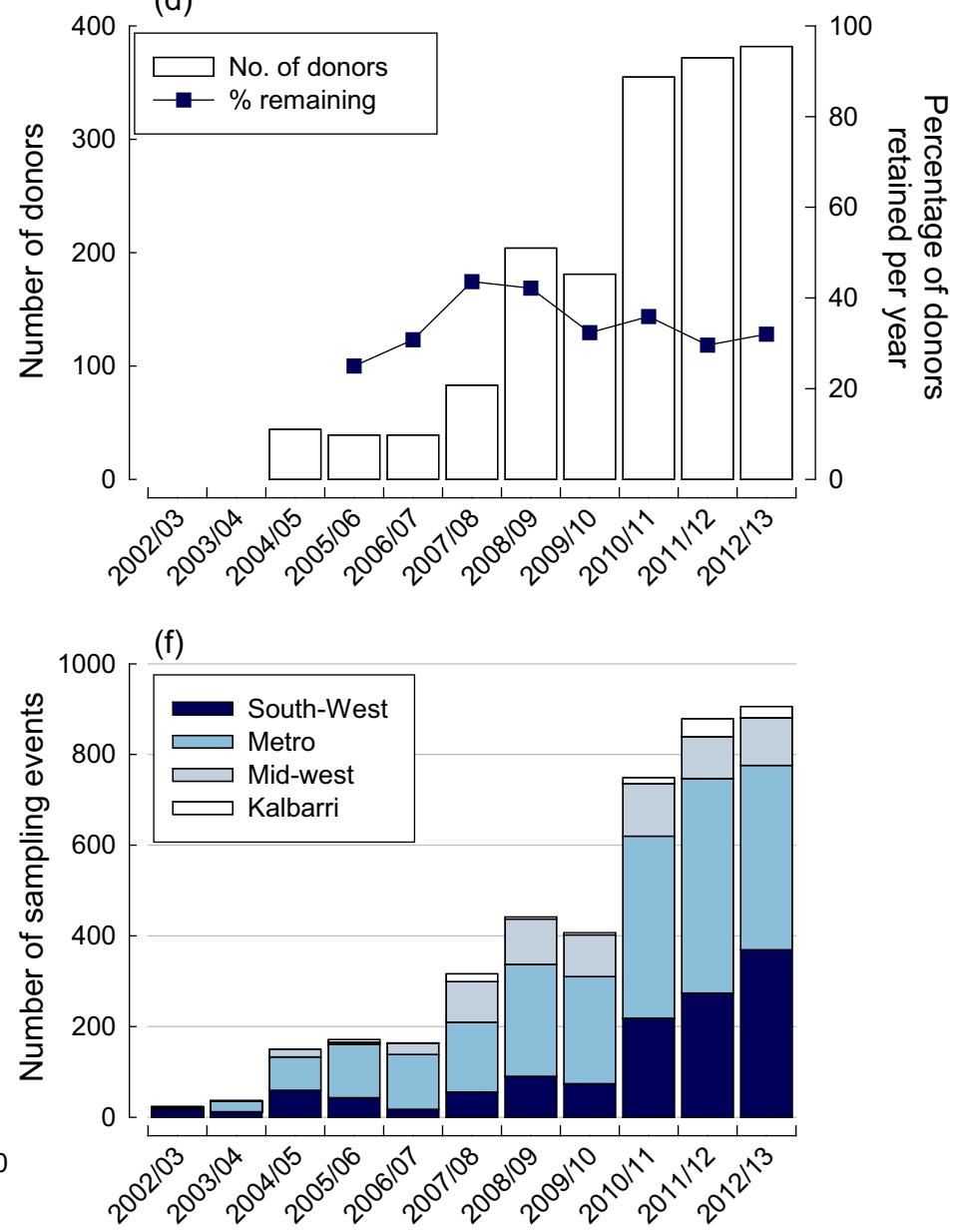

Fiscal year

Figure $2 \mid$ Progress of sampling success and fisher involvement before and after Send us your skeletons commenced in 2010/11. (a) Total number of skeletons collected from recreational fishers in each management area of the West Coast Bioregion, (b) number of West Australian dhufish, Snapper and Baldchin groper skeletons obtained, (c) percentage of the total number of skeletons collected from recreational fisher donations, fishing competitions and monthly fishing club meetings, (d) number of donors of skeletons per year and percentage of donors retained per year, (e) numbers of fishers donating different numbers of skeletons in 2010/11-2012/13 and (f) number of sampling events (an event comprises a sample of $\geq 1$ fish skeleton caught and donated on a single day by an individual fisher) in each management area.

locations (i.e. 49), which tended to be spread more broadly, and this was also the case in both the Metropolitan and South-west Areas (Fig. 4b). While this was also true in the Mid-west Area, many of the samples were obtained from one general location in both years due mainly to greater sampling effort by staff at that location and the limited number of drop-off locations across the Mid-west Area. Specific location information, such as latitude/longitude or a grid map reference, was almost never obtained prior to 2007/08. Since 

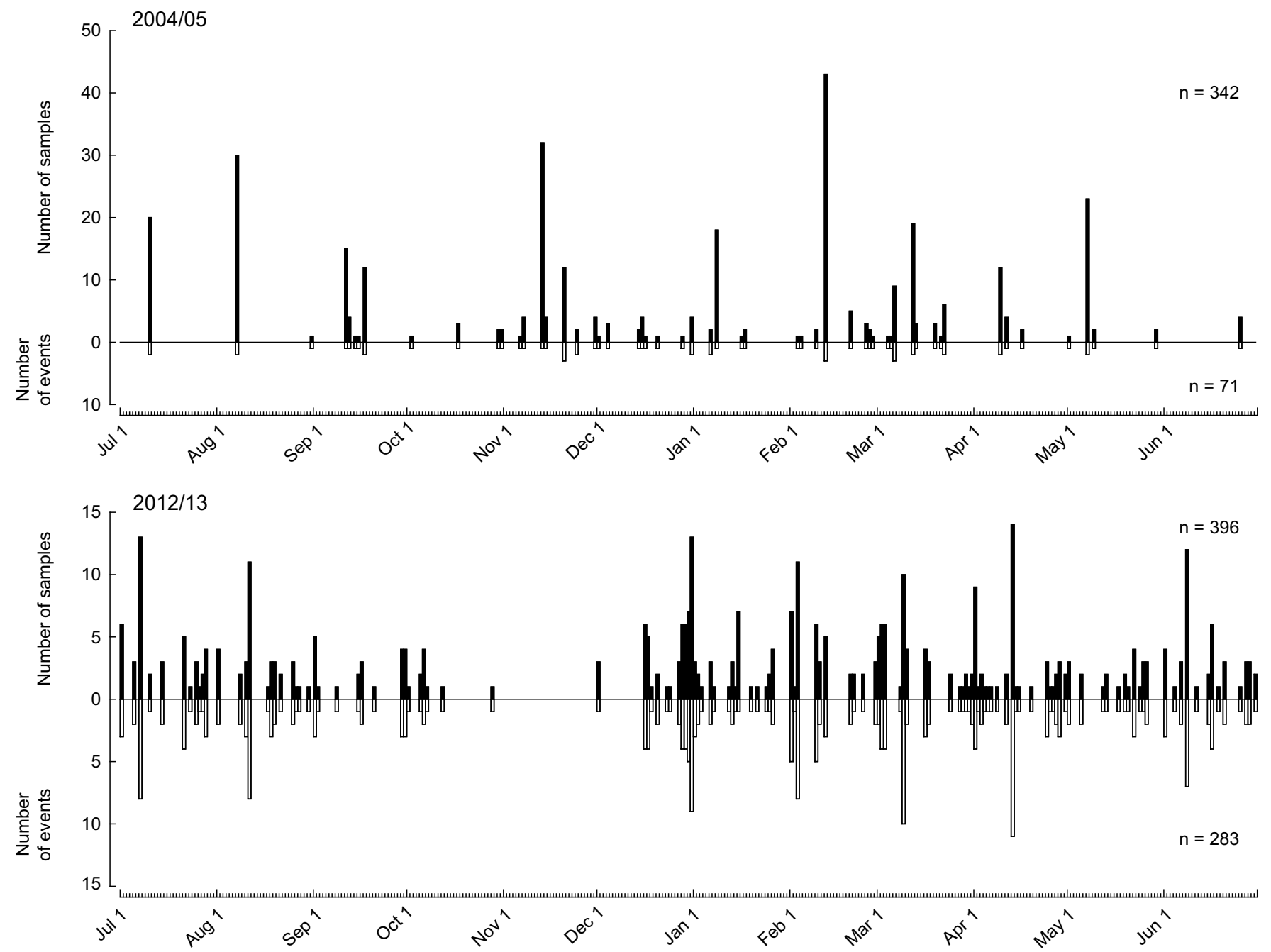

Figure 3 Change over time in the numbers of samples and sampling events for West Australian dhufish. Number of West Australian dhufish skeleton samples collected in the Metropolitan Area per day (above the reference line) and number of sampling events per day, i.e. individual samples (of one or more dhufish skeleton) donated by a fisher on a given date (below the reference line), in 2004/05 vs 2012/13. Total number of samples and events shown on each graph.

$2007 / 08$, the percentage of samples with specific location information, which is treated as confidential, has increased substantially, but has also varied greatly from only $19 \%$ up to $60 \%$ of samples per year, making it difficult to examine spatial representativeness at smaller scales.

Economic cost of traditional fish skeleton collection vs Send us your skeletons. To compare the cost of the different approaches to fish skeleton collection, i.e. sampling dominated by active collection vs sampling dominated by voluntary donations, we have estimated the costs of sampling according to the regimes employed in each year between 2002/03 and 2012/13. Current prices (2013/14) were used to cost the different regimes to be able to evaluate what it would cost if a research organisation adopted a specific regime today.

Between 2002/03 and 2006/07, a limited number of staff were employed (one research scientist and one or two technical officers) to conduct sampling and there was little promotion of the need for fish skeletons (Supplementary Table S1). The Department increased the number of staff dedicated to this program and its promotion of the need for skeleton donations in 2007/08 to increase sampling success. In 2007/08, the active sampling regime and resources required (e.g. staff, field, lab, equipment and promotion costs) would have incurred ca 1.5 times the cost of the 2004/05 sampling regime (at 2013/14 prices), due mainly to more staff being employed to achieve sampling targets (Fig. 5a). However, in 2007/08, more than double the number of skeletons were obtained than in 2004/05, which would have equated to a reduction in the cost per skeleton of about 39\% (Fig. 5a, b). The greatest total expenditure occurred in 2010/11 and 2011/12, i.e. ca 1.6 times 2004/05 costs, after SUYS commenced, which was due mainly to a large increase in promotional costs. But this was reduced to 1.5 times 2004/05 costs by $2012 / 13$, as a result of reductions in those initial promotional costs. However, the much larger number of skeletons collected in the three years after SUYS commenced (3.2-4.5 times the number collected in 2004/05) would have resulted in the total cost/skeleton decreasing by $52-62 \%$ of estimated costs in 2004/05 (at 2013/14 prices) (Fig. 5a, b).

Social impact of Send us your skeletons. The online survey was completed by 249 people and, of those, approximately $88 \%$ of people were aware of SUYS, 76\% understood what it was about and $81 \%$ were happy to receive further information (see Supplementary Table S2). Also, in further questioning of people that knew of SUYS, $46 \%$ of 123 respondents identified that they were supportive of the program and understood its need. However, $59 \%$ of people that knew of SUYS had never donated skeletons and only $5.5 \%$ of the 123 people donated on a regular basis (monthly). This is in stark contrast to the fact that $73 \%$ go fishing at least once a month. Respondents indicated that it was inconvenient to donate 


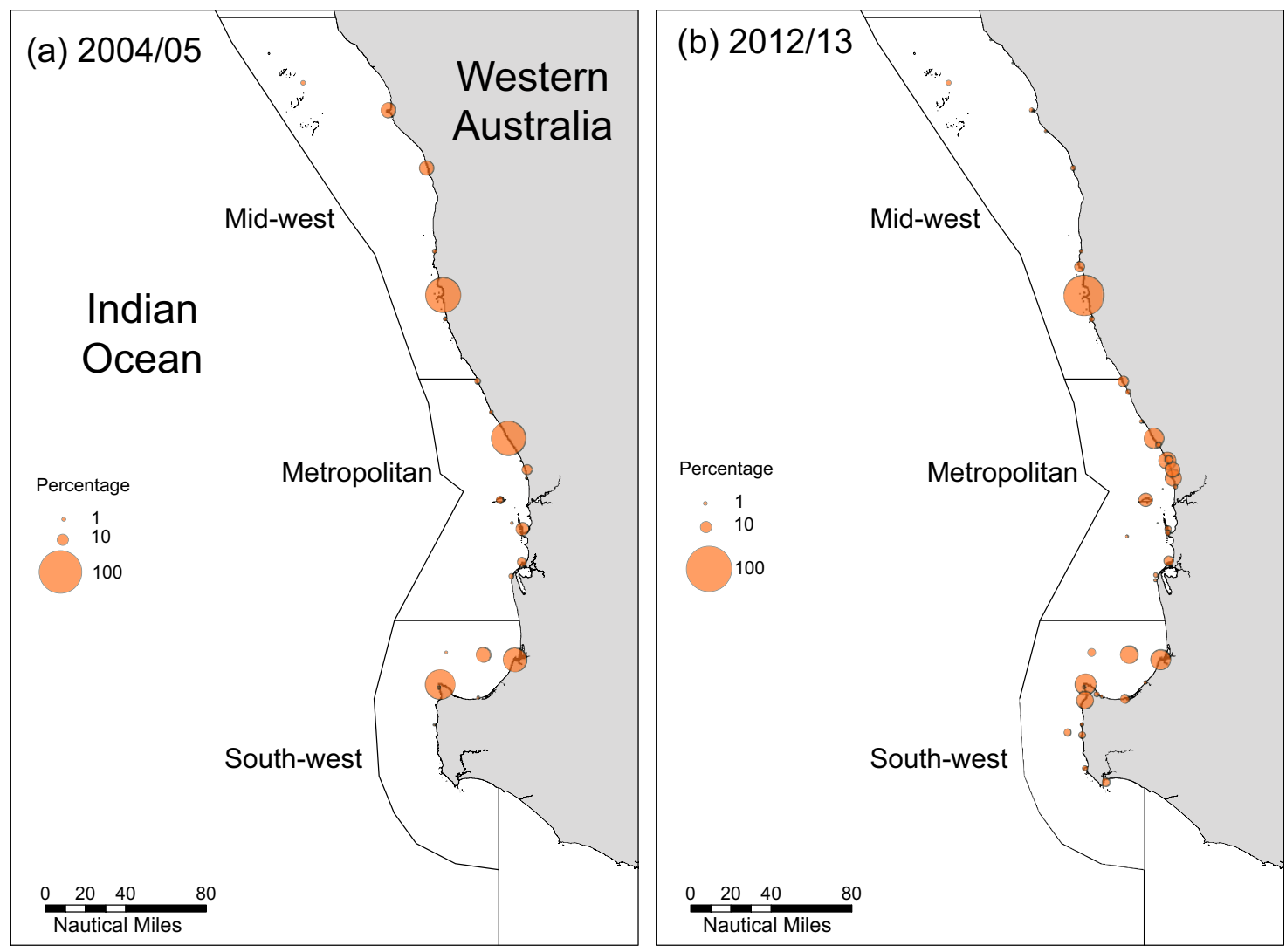

Figure 4 | Change over time in the spatial coverage of West Australian dhufish skeleton samples. General locations of sample origins of West Australian dhufish in each management area during (a) 2004/05 and (b) 2012/13. In each management area (Mid-west, Metropolitan, South-west), orange circles $(\bigcirc)$ represent the percentage of skeleton samples from each location for that area. Circle size is proportional to percentage. Map created by B.M.C. in ArcGIS ArcMap v. 10.

skeletons in $34 \%$ of cases, while $16 \%$ indicated that they didn't donate skeletons either because they thought the data may be used to restrict fishing access, or didn't understand how it related to them. Another $60 \%$ provided a range of responses, which largely related to the difficulty of donating skeletons, e.g. too far to travel to drop-off locations. Among fishers that had donated skeletons $(\mathrm{n}=91)$, $47 \%$ indicated that winning a prize did not influence their decision to donate skeletons, while for $35 \%$, it was a factor. Of those 91 donors, $43 \%$ indicated that interaction with Department staff had an influence on their decision and $30 \%$ believe it was a good way to get rid of fish waste. Most importantly, $93 \%$ of the 91 donors, stated that they were donating because they were 'contributing to sustainability', while $51 \%$ wanted to set a good example to their children.

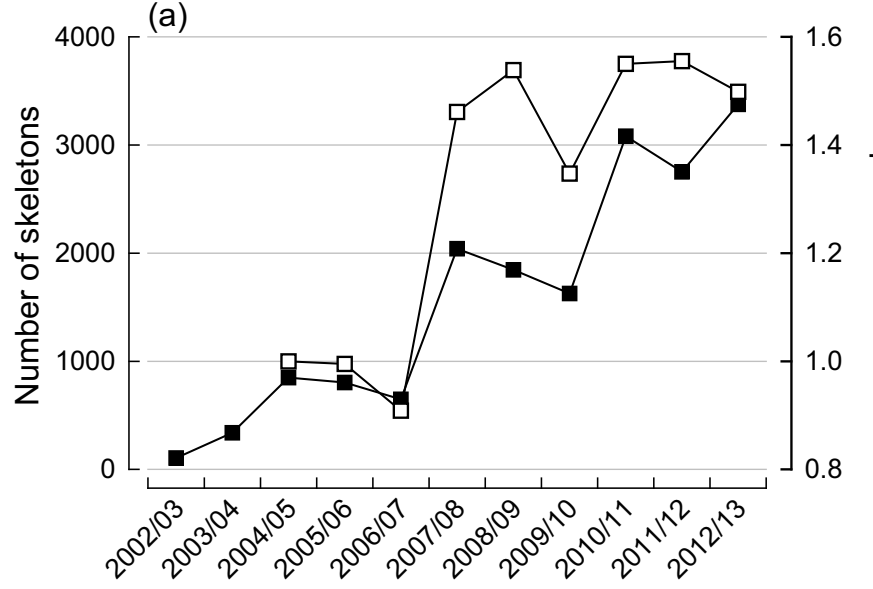

Period

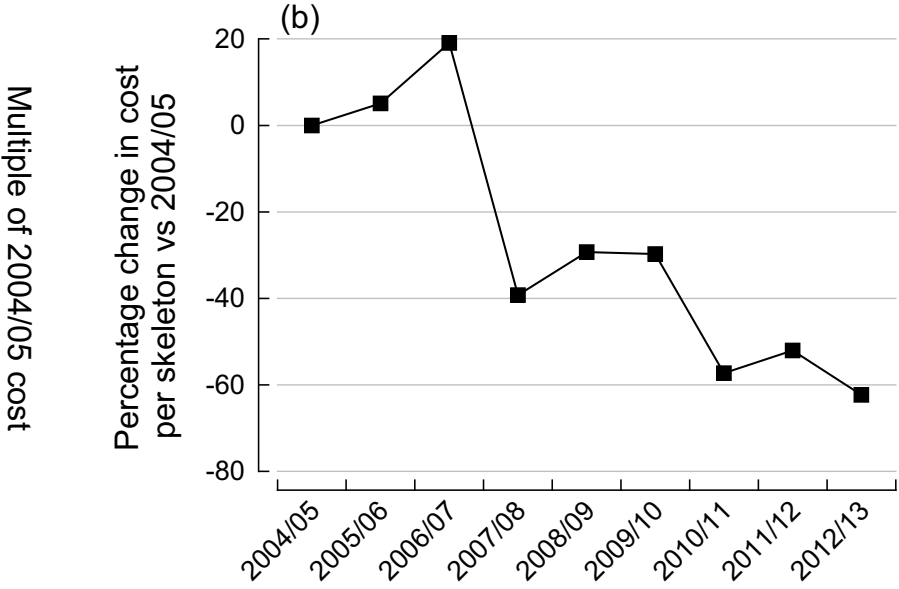

Period

Figure $5 \mid$ Change over time in the total number of skeleton samples obtained and the cost of collection. (a) Number of fish skeletons obtained from the recreational sector between 2002/03 and 2012/13 ( $\mathbf{\square}$ ) and the cost of collection (as a multiple of the 2004/05 collection cost; $\square$ ). (b) The percentage change in cost per skeleton relative to $2004 / 05$ to run the program according to each year's sampling regime. 


\section{Discussion}

The Send Us Your Skeletons (SUYS) citizen science program has realised significant benefits towards conducting stock assessments of important demersal fish species. The program has achieved a substantial increase in involvement of the recreational fishing community of Western Australia in its first three years, reflected in a sustained increase in both the number of donors and the number of biological samples voluntarily donated each year. This indicates a willingness to assist with the monitoring program and an understanding of both the sustainability needs and social value of the demersal fish resource. The samples collected during SUYS have also helped to improve the representativeness of data available for stock assessments by increasing the proportion of the recreational catch of each species that was sampled and the temporal and spatial coverage of samples ${ }^{18,42-44}$.

Another benefit of SUYS, critical for its long-term viability, has been the reduction in the annual cost of collection per fish skeleton by about $50-60 \%$ of what costs would be if an active sampling regime was adopted today. While the total annual cost to the Department to collect fish skeletons has increased over time, with more staff and increased promotion required to operate SUYS, this program can cost-effectively produce the data necessary for timely stock assessments, greatly improving the likelihood of ongoing funding. Furthermore, a citizen science approach to data collection on the west coast of Australia would be significantly cheaper than largescale stratified sampling via chartered or research vessels, which would require significant field time to obtain the necessary sample numbers per species/sector/management area/year with appropriate intra-annual temporal and spatial coverage. This is because the most effective method of capture (line fishing) for these reef species is intensive, catch rates are highly variable ${ }^{41}$ and methods such as trawling, commonly used elsewhere ${ }^{25,31}$, are either not suitable or effective in their reef habitats.

Despite the benefits that citizen science programs can offer, their use in the collection of biological data from recreational fishers for fisheries stock assessments, in the way that SUYS operates, appear to be rare, given the lack of discussion in the published literature. The SUYS program has benefited the collection of data on the age compositions of the catch of each of the key species. These data are necessary for estimating rates of fishing mortality $(F)$ using catch curve methods, the current approach to assessing stocks of those species. However, when other relevant data become available, such as standardised catch rates, these age compositions could potentially be used in more complex stock assessment models which estimate the biomass of stocks. Increasing sample sizes via SUYS may help to improve the precision of age estimates being used ${ }^{44,45}$ and the better spatial and temporal coverage and greater diversity of the sources of samples (many different fishers, more sampling events and turnover of donors) have reduced clustering and are likely to have increased sample randomness and independence, leading to a better representation of the stocks of each species and greater accuracy of estimates of stock status ${ }^{46}$. This would lead to reduced uncertainty about the accuracy of $F$ estimates. In addition, there is evidence to indicate that other potential sampling effects on age structures derived from recreational sector samples may have been reduced through the SUYS program. For example, samples obtained via voluntary donations by recreational fishers through SUYS comprised a more complete range of fish ages than those that were obtained through clubs and fishing competitions, which is probably related to the limited times, locations and number of people associated with the latter sampling approach. Thus, SUYS is likely to have produced more representative age structures than traditional sampling of the recreational sector, by reducing the effect of the smaller number of individual fishers involved in earlier sampling years, e.g. the targeting or selection of fish, choice of hook type or size and fishing location ${ }^{47-49}$. These types of effects have perhaps been perceived as difficult to overcome with a citizen science approach to sampling, as reflected in their limited adoption. In contrast, the ability to control certain variables, such as the location or time of sampling, with stratified fishery-independent regimes is a significant advantage and is reflected in their frequent use, despite their substantial expense $e^{31,34}$. Thus, in implementing a citizen science program to collect age structure data for stock assessments, it is prudent to investigate and account for the effects of different sampling programs to attempt to reduce or eliminate them, in addition to a comparison of costs ${ }^{30,47}$.

Another issue overcome by increased voluntary sample donation from the recreational sector was identified in the $F$ estimates (and their trajectory over time) produced in a recent assessment of the three demersal species, which were derived separately for recreational and commercial samples of each species in each management area. The results from the different sources of samples were largely consistent $^{41}$. However, a difference in the age compositions of West Australian dhufish, derived from commercial and recreational samples in the South-west Area, was identified. The commercial samples comprised a smaller proportion of older fish than the recreational samples and produced a much higher $F$ estimate. Furthermore, the trajectory for $F$ between assessment periods, when using age structure data from commercial samples, was inconsistent with that from the recreational data and data from both the commercial and recreational sectors in the other management areas ${ }^{41}$. This was attributed to the fact that commercial fishing for West Australian dhufish in the South-west Area occurs largely on fish that are aggregating to spawn in a relatively restricted part of that management area in the austral summer (typically December and January). Therefore, the samples derived from these catches were spatially and temporally restricted. However, recreational fishers tend to fish throughout the year and across a much greater part of the South-west Area. Thus, the presence of a greater number of older fish in recreational fisher samples suggests that they may be more representative of the broader stock in that area. While this identified difference does not limit the value of the data obtained from the commercial sector, or from recreational clubs or competitions, having multiple data sets does highlight the benefit of being able to explore differences associated with each sample source ${ }^{47}$ and the importance of ongoing community involvement from both sectors.

The SUYS program has become critical to the Department of Fisheries' ability to assess the recovery of stocks of key demersal species along the west Australian coast and particularly important in the Metropolitan Area, where the commercial fishery is now prohibited from operating. A management strategy to recover stocks of demersal species and performance indicators ( $F$ estimates vs biological reference points) to identify whether that is occurring have been established. Simulation analyses indicated that given the biology of the species and the management in place, full stock recovery could take in the order of 15-20 years. If sufficient appropriate data and resources are available, further management strategy evaluation analyses could be worthwhile, to consider among other things, the time required for stocks to recover under alternate management regimes, potential management strategies pre- and post- stock recovery and consideration of different sampling approaches, e.g. sampling commercial vs recreational catch $^{45}$. Ultimately, the long-term value of this contributory citizen science program is dependent on it producing appropriate information for management and an equivalent or even more accurate assessment of stock status than from a traditional data collection approach, regardless of the difference in $\operatorname{cost}^{37,41}$.

The numbers of recreational fishers that have become involved in the SUYS program perhaps reflect the fact that community involvement in citizen science programs has become extremely popular. This is because it can lead to improved relationships and knowledge flow among members of the public and scientists and to greater trust and more-widely accepted science and management decisions ${ }^{10,50}$. 
This may be reflected, to a certain extent, in the results of our online survey. However, there are no available data to assess whether this demonstrated a change in attitudes over time, i.e. prior to and after SUYS commencing. Notwithstanding the potential biases of online surveys, such as non-response bias ${ }^{51}$, the survey of 249 people indicated that there was an understanding of and support for SUYS and the Department's role in managing aquatic resources. Furthermore, making a contribution to sustainability and setting a good example to children was a strong motivation behind fishers donating samples.

The degree of turnover of donors per year and the need to continue attracting fishers to participate is a challenge for the SUYS program to address in the future to ensure its longevity. Improving skeleton collection services and feedback may increase participation, but longevity will rely to a certain extent on behaviour change by recreational fishers, reflected in their willingness to donate skeletons at their own expense. It is critical for the public to recognise that their direct involvement is important to ensuring sustainability of fish resources in Western Australia and this also applies to other countries with significant recreational fisheries, particularly those without the resources to fund fishery-independent sampling ${ }^{52}$. This may become an even more important issue as populations grow, potentially resulting in larger recreational fishing populations and greater pressure on fish stocks ${ }^{53}$. Although in certain situations (e.g. regions with large human populations), such programs may result in more fish samples being donated than a research organisation could logistically manage, two-stage sampling or sub-sampling of donations could be used to overcome this to some extent. Despite this potential issue, resource management agencies still need to encourage public engagement in such programs in some form and provide appropriate financial resourcing for them ${ }^{52}$. Indeed, the need for community engagement, with respect to programs such as SUYS, also requires a focus on educating the next generation(s) of fishers, i.e. school children, to engage them from an early age. For example, the Department's Naturaliste Marine Discovery Centre (NMDC) educates 3,000-5,000 students per year about fish biology and fisheries and the importance of programs such as SUYS.

The contributory citizen science program SUYS has provided significant benefits to the Department associated with increases in recreational fisher involvement, including improved sample sizes, representativeness and sampling cost-effectiveness and there is recognition of the importance of SUYS in the community. SUYS is providing tangible benefits to management by way of more timely stock assessments informed by improved data sets, leading to high quality management advice for demersal species in the WCB. It has also been successfully employed to support assessments of nearshore coastal species in both the WCB and South Coast Bioregions (SCB) of Western Australia ${ }^{17,54,55}$ and more recently expanded to include monitoring of demersal species in the SCB and as a platform for collection of data-limited deep-water demersal species (200-600 m), which are of growing interest to recreational fishers ${ }^{56,57}$ in Western Australia. The benefits of SUYS have also been recognised by fisheries institutions elsewhere in Australia, where similar programs have recently been constructed (Keen Angler Program, http://www.daff.qld.gov.au/; Research Angler Program, http://www.dpi.nsw.gov.au/).

The key to the future of citizen science programs such as SUYS are the recreational fishers who are critical to sample collection, but also its most important proponents, being able to readily communicate with other fishers. The Department needs to convey the importance of this role to trigger their involvement and increase ownership of fish resources. Increasing involvement in the scientific process may also lead to greater understanding and acceptance of management decisions ${ }^{25}$, which is critical for the long-term sustainability of fish stocks ${ }^{10,58}$.

\section{Methods}

Stock assessment data needs from the recreational sector. Stock assessments by the Department of Fisheries Western Australia ('the Department') of three commercially and recreationally important fish species (West Australian dhufish Glaucosoma hebraicum, Snapper Chrysophrys auratus and Baldchin groper Choerodon rubescens) on the west coast of Australia evaluate the effect of fishing (fishing mortality rates via catch curve analyses) and implicitly, the effects of the wider ecosystem (total mortality rates), using biological data obtained from fish skeletons (remains of the fish after filleting) collected from both the commercial and recreational sectors in the West Coast Bioregion (WCB $)^{41}$. The assessments of fishing mortality rates $(F)$ for each species are conducted separately on data collected from each sector over three years in each management area. The $F$ estimates are then compared with internationallyaccepted biological reference points to determine stock status ${ }^{41}$. The biological data obtained from fish skeletons, contain, in particular, the otoliths (ear bones), which are used for determining the age of a fish and resultant population age structures ${ }^{29,59,60}$. A random sample of $\geq 500$ skeletons (of legal-sized fish) per species (three species), per management area (up to three areas, depending on which area they are important in catches of each sector; Table 1; see Fig. 4), per year of sampling (each year for three years), is sought from recreational fishers to conduct such assessments, totalling an ideal 10,500 skeletons from that sector ${ }^{43}$. A similar number of skeletons of the three species are obtained from the commercial sector via sampling of fish markets. The combination of different data sets provides the necessary geographic coverage and complementary age structures to assess stocks of the species and also allows evaluation of any differences among data sets from the two sectors.

The structure of Send us your skeletons. Prior to 2007/08, skeletons from recreational fishers were obtained primarily at periodic annual fishing competitions, monthly within-club competitions of a small number of clubs and via a small number of fishers enlisted to "self-sample", each of which continue to some extent. However, to obtain necessary sample numbers from the recreational sector for species/area combinations where this was not occurring each year and improve spatio-temporal representativeness, limited ad hoc promotion of the need for a greater number of fish skeletons from recreational fishers began in 2007/08. This occurred just before management changes and included the distribution of promotional flyers to Department offices and some fishing-related shops in the WCB, occasional newspaper articles and Department webpage material. As sample size targets were still difficult to achieve, the Department subsequently launched the branded and better-publicised SUYS program at the end of 2010 to improve sampling of the recreational sector.

The SUYS program requests recreational fishers in the WCB to voluntarily donate fish skeletons of the three demersal species. Fishers thus have the responsibility for the sampling process, including the selection of species, location and date of capture and quantity (within regulations) of the sample. With each sample, fishers are required to provide their name, address and phone number, plus the date and location of capture (either a GPS position or a distance and bearing from port and name of port). They are also required to travel to present samples at one of 20 drop-off locations in the WCB. Samples are later collected by scientists from the Department, who extract biological data in the laboratory for each species, including fish length, sex, reproductive development stage and otoliths (ear bones). Briefly, the otoliths are transversely sectioned using a bone saw. After setting the section on a microscope slide, growth rings (much like those in trees) are counted by viewing the slide under a dissecting microscope and the counts are used to determine the age of each fish ${ }^{29,59,60}$.

Promotion strategy. The SUYS program was launched following a strategic communication plan agreed upon between scientists and community relations staff of the Department. This incorporated (1) a media campaign (e.g. newspaper and fishing magazine articles, radio interviews, webpage material), (2) events (e.g. boat ramp filleting events, promotion at public boat/marine equipment shows and regional agricultural shows), (3) production and distribution of new flyers to 43 fishing-related stores, (4) the placement of signs advertising SUYS at 30 boat ramps, (5) an increase in the numbers and advertisement of locations where fishers could drop off fish skeletons and (6) the enhancement of reward systems. The latter included instant rewards at the time of skeleton donation (e.g. water bottles and drink coolers), plus quarterly and end of year prize draws, with prizes donated by fishing-related companies (e.g. a one-week charter fishing trip for two people worth approximately $\$ 7,000$ ).

Feedback. An annual newsletter about the progress of SUYS was sent to each recreational fisher who donated skeletons each year, along with a personal letter detailing the biological data (length, age and estimated weight) from the fish they donated and a reward (e.g. t-shirt or hat). The annual newsletter was also distributed to fisheries offices and participating shops and placed on the Department's webpage (www.fish. wa.gov.au/frames).

Public online survey. An online survey of the public was conducted in 2011 to gain an understanding of (1) the awareness of recreational fishers of the SUYS program and their willingness to be involved, (2) why fishers did not donate skeletons if they were aware of the program and understood the need for it and (3) whether prizes were seen as an incentive to fishers to donate skeletons. The request to complete the survey was promoted through newspaper articles, on the Department's webpage and to all Recreational Boat Fishing Licence holders. Questions in the survey are detailed in the Results.

Analysis of change in temporal and spatial coverage of samples prior to and after the commencement of Send us your skeletons. To provide an example of the change in temporal and spatial coverage of samples, prior to and after SUYS commenced, and thus using two different approaches to sampling, data for West Australian dhufish 
from 2004/05 and 2012/13 were chosen. 2004/05 was chosen as a year representative of sampling prior to SUYS commencing as it comprised a year when (1) samples were obtained using traditional approaches of active sampling at fishing clubs and selfsampling largely by enlisted fishers, (2) there was no large-scale media promotion, (3) substantial sampling effort occurred in that year and thus a reasonable number of samples were collected via traditional approaches to be able to present a meaningful comparison and (4) suitable information was available in that year on recreational fisher names and dates of capture to facilitate the comparison. 2012/13 was chosen as an example year of sampling after SUYS commenced as (1) SUYS only commenced part way through 2010/11, thus it did not provide a full year of data, (2) it was based on the almost exclusively voluntary donation of samples (and met other requirements, i.e. sample information including fisher name and date of capture were available) and (3) using data from the most recent year available had allowed time for the program to become established and may have been more representative of such a program in the longer term. Good general location information for each sample has been obtained throughout the period from 2002/03 to $2012 / 13$.

Cost of fish skeleton collection. Quantification of activities employed in the monitoring and assessment program was conducted for each year between 2002/03 and 2012/13. This included determining the number and employment level of research staff, field trip expenses (e.g. number of staff and field days), laboratory and field equipment required, the number of vehicles leased and number and type of promotional activities. Costs were then applied to each of these activities based on current (2013/14) prices, except for actual costs of promotion of SUYS since 2010/11. This allowed comparison of what the cost at today's prices would be to use the sampling regime adopted in each year prior to SUYS (i.e. using more active sampling of recreational fishers) with that for SUYS (a contributory citizen science program plus limited active sampling). This avoids the effect that changes in costs over time would have, e.g. due to the Consumer Price Index or progression of individual staff members along salary scales.

A year of substantial sampling effort (2004/05), using predominantly active sampling (towards an assessment based on three years of data collection between 2002/03 and 2005/06), was also a year during which the most skeletons were obtained from the recreational sector for a single assessment. This was chosen as a base year against which to compare subsequent annual costs of collection per fish skeleton.

1. Shirk, J. L. et al. Public participation in scientific research: a framework for deliberate design. Ecol. Soc. 17, Article 29 (2012).

2. Cohn, J. P. Citizen science: Can volunteers do real research? Bioscience $\mathbf{5 8}$ 192-197 (2008).

3. Bonney, R. et al. Citizen science: A developing tool for expanding science knowledge and scientific literacy. Bioscience 59, 977-984 (2009).

4. Silvertown, J. A new dawn for citizen science. Trends Ecol. Evol. 24, 467-71 (2009).

5. Devictor, V., Whittaker, R. J. \& Beltrame, C. Beyond scarcity: citizen science programmes as useful tools for conservation biogeography. Divers. Distrib. 16, 354-362 (2010)

6. Dickinson, J. L., Zuckerberg, B. \& Bonter, D. N. Citizen Science as an ecological research tool: Challenges and benefits. Annu. Rev. Ecol. Evol. Syst. 41, 149-172 (2010).

7. Ryan, R. L., Kaplan, R. \& Grese, R. E. Predicting volunteer commitment in environmental stewardship programmes. J. Environ. Plan. Manag. 44, 629-648 (2001).

8. Leslie, L. L., Velez, C. E. \& Bonar, S. A. Utilizing volunteers on fisheries projects. Fisheries 29, 10-14 (2004).

9. Smith, K. An army of observers. Nat. Clim. Chang. 1, 79-82 (2011)

10. Tulloch, A. I. T., Possingham, H. P., Joseph, L. N., Szabo, J. \& Martin, T. G. Realising the full potential of citizen science monitoring programs. Biol. Conserv. 165, 128-138 (2013).

11. Stallings, C. D. Fishery-independent data reveal negative effect of human population density on Caribbean predatory fish communities. PLoS One 4, e5333 (2009)

12. Marshall, N. J., Kleine, D. A. \& Dean, A. J. CoralWatch: education, monitoring, and sustainability through citizen science. Front. Ecol. Environ. 10, 332-334 (2012)

13. Pollock, K. H., Jones, C. M. \& Brown, T. L. Angler Survey Methods and their Applications in Fisheries Management 371 (American Fisheries Society, 1994).

14. Willis, T. J., Millar, R. B. \& Babcock, R. C. Detection of spatial variability in relative density of fishes: comparison of visual census, angling, and baited underwater video. Mar. Ecol. Prog. Ser. 198, 249-260 (2000).

15. Smith, K. A., Hammond, M. \& Brown, J. A Summary of Data Collected by the Angler's Daily Log Book and Fishing Tournament Monitoring Programs in 20042006. Fisheries Occasional Publication No. 4059 (2007). http://www.fish.wa.gov. au/About-Us/Publications/Pages/default.aspx Date of access: 02/04/2014.

16. Kleiven, A. R., Olsen, E. M. \& Vølstad, J. H. Total catch of a red-listed marine species is an order of magnitude higher than official data. PLoS One 7, e31216 (2012).

17. Smith, K. et al. Status of Nearshore Finfish Stocks in South-western Western Australia Part 2: Tailor. NRM Project 09003 Final Report. Fisheries Research Report No. 247108 (2013). http://www.fish.wa.gov.au/Documents/research_ reports/frr247.pdf Date of access: 02/04/2014.
18. Ryan, K. L. et al. An Integrated System to Survey Boat-based Recreational Fishing in Western Australia 2011/12, Fisheries Research Report No. 249168 (2013). http:// www.fish.wa.gov.au/Documents/research_reports/frr249.pdf Date of access: 02/ 04/2014.

19. Russ, G. R., Lou, D. C. \& Ferreira, B. P. Temporal tracking of a strong cohort in the population of a coral reef fish, the coral trout, Plectropomus leopardus (Serranidae: Epinephelinae), in the central Great Barrier Reef, Australia. Can. J. Fish. Aquat. Sci. 53, 2745-2751 (1996).

20. Committee on fish stock assessment methods. Improving Fish Stock Assessments 188 (National Academy Press, 1998).

21. Newman, S. J. \& Dunk, I. J. Age validation, growth, mortality, and additional population parameters of the goldband snapper (Pristipomoides multidens) off the Kimberley coast of northwestern Australia. Fish. Bull. 101, 116-128 (2003)

22. Johnson, T. R. \& Van Densen, W. L. T. Benefits and organization of cooperative research for fisheries management. ICES J. Mar. Sci. 64, 834-840 (2007).

23. Fisheries Queensland. Fisheries Long Term Monitoring Program Sampling Protocol - Rocky Reef Fish (2010 Onwards) Section 17 (2010). at http://www.daff. qld.gov.au/_data/assets/pdf_file/0010/52966/Rocky-Reef-Fish-SP1-2010onwards.pdf Date of access: 02/04/2014.

24. Jacobsen, R. B., Wilson, D. C. K. \& Ramirez-Monsalve, P. Empowerment and regulation - dilemmas in participatory fisheries science. Fish Fish. 13, 291-302 (2012).

25. Armstrong, M. J., Payne, A. I. L., Deas, B. \& Catchpole, T. L. Involving stakeholders in the commissioning and implementation of fishery science projects: experiences from the U.K. Fisheries Science Partnership. J. Fish Biol. 83, 974-996 (2013)

26. Quinn, T. J. \& Deriso, R. B. Quantitative Fish Dynamics 542 (Oxford University Press, 1999).

27. Lenanton, R. C., Ayvazian, S. G., Pearce, A. F., Steckis, R. A. \& Young, G. C. Tailor (Pomatomus saltatrix) off Western Australia: where does it spawn and how are the larvae distributed? Mar. Freshw. Res. 47, 337-346 (1996)

28. Fairclough, D. V., Dimmlich, W. F. \& Potter, I. C. Reproductive biology of the Australian herring Arripis georgiana. Mar. Freshw. Res. 51, 619-630 (2000)

29. Hesp, S. A., Potter, I. C. \& Hall, N. G. Age and size composition, growth rate reproductive biology, and habitats of the West Australian dhufish (Glaucosoma hebraicum) and their relevance to the management of this species. Fish. Bull. 100, 214-227 (2002).

30. Marriott, R. J. et al. Age-based demographic assessment of fished stocks of Lethrinus nebulosus in the Gascoyne Bioregion of Western Australia. Fish. Manag. Ecol. 18, 89-103 (2011).

31. Starr, P. Fisher-collected sampling data: Lessons from the New Zealand experience. Mar. Coast. Fish. Dyn. Manag. Ecosyst. Sci. 2, 47-59 (2010).

32. Hilborn, R. \& Walters, C. J. Quantitative Fisheries Stock Assessment: Choice, Dynamics and Uncertainty 570 (Chapman and Hall, 1992).

33. Rotherham, D., Underwood, A. J., Chapman, M. G. \& Gray, C. A. A strategy for developing scientific sampling tools for fishery-independent surveys of estuarine fish in New South Wales, Australia. ICES J. Mar. Sci. 64, 1512-1516 (2007).

34. Ono, K. et al. The importance of length and age composition data in statistical agestructured models for marine species. ICES J. Mar. Sci. Adv. Access (2014). http:// icesjms.oxfordjournals.org/content/early/2014/02/20/icesjms.fsu007.full. pdf + html Feb 20, 2014

35. Fairclough, D., Lai, E., Holtz, M., Nicholas, T. \& Jones, R. West Coast Demersa Scalefish Resource Status Report. In Status Reports of the Fisheries and Aquatic Resources of Western Australia 2012/13. State of the Fisheries (eds. Fletcher, W. J. \& Santoro, K.) 91-101 (Department of Fisheries Western Australia, 2013). www. fish.wa.gov.au Date of access: 25/08/2014.

36. Department of Fisheries Western Australia. A Strategy for Managing the Recreational Catch of Demersal Scalefish in the West Coast Bioregion Fisheries Management Paper No. 228. 26 (2008). http://www.fish.wa.gov.au/Documents/ management_papers/fmp228.pdf Date of access: 25/08/2014.

37. Wise, B. S., StJohn, J. \& Lenanton, R. C. Spatial Scales of Exploitation Among Populations of Demersal Scalefish: Implications for Management. Part 1: Stock Status of the Key Indicator Species for the Demersal Scalefish Fishery in the West Coast Bioregion. Fisheries Research Report no. 163130 (2007). http://www.fish.wa. gov.au/Documents/research_reports/frr163.pdf Date of access: 02/04/2014.

38. Caddy, J. F. \& Mahon, R. Reference Points for Fisheries Management. FAO Fisheries Technical Paper No. 34783 (1995). http://www.fao.org/docrep/003/ V8400E/V8400E00.HTM Date of access: 25/08/2014.

39. Caddy, J. F. \& Agnew, D. J. An overview of recent global experience with recovery plans for depleted marine resources and suggested guidelines for recovery planning. Rev. Fish Biol. Fish. 14, 43-112 (2004).

40. Crowe, F. M., Longson, I. G. \& Joll, L. M. Development and implementation of allocation arrangements for recreational and commercial fishing sectors in Western Australia. Fish. Manag. Ecol. 20, 201-210 (2013).

41. Fairclough, D. V. et al. Status of Demersal Finfish Stocks on the West Coast of Australia. Fisheries Research Report No. 25392 (2014). http://www.fish.wa.gov.au/ Documents/research_reports/frr253.pdf Date of access: 25/08/2014.

42. Integrated Fisheries Allocation Advisory Committee. West Coast Demersal Scalefish Allocation Report. Fisheries Management Paper No. 24960 (2013). http:// www.fish.wa.gov.au/Documents/management_papers/fmp249.pdf Date of access: $02 / 04 / 2014$ 
43. Craine, M. et al. Determination of a Cost Effective Methodology for Ongoing Age Monitoring Needed for the Management of Scalefish Fisheries in Western Australia. Final FRDC Report - Project 2004/042. Fisheries Research Report No. 19298 (2009). http://www.fish.wa.gov.au/Documents/research_reports/frr192. pdf Date of access: 02/04/2014.

44. Campana, S. Accuracy, precision and quality control in age determination, including a review of the use and abuse of age validation methods. J. Fish Biol. 59, 197-242 (2001).

45. Fisher, E. A., Hesp, S. A. \& Hall, N. G. Exploration of the Effectiveness of Alternative Management Responses to Variable Recruitment. Final Report to the Fisheries Research and Development Corporation Project No. 2008/006 167 (2011). http:// frdc.com.au/research/final-reports/Pages/2008-006-DLD.aspx Date of access: 25/ $08 / 2014$.

46. Aanes, S. \& Pennington, M. On estimating the age composition of the commercial catch of Northeast Arctic cod from a sample of clusters. ICES J. Mar. Sci. 60 297-303 (2003).

47. Chen, Y., Chen, L. \& Stergiou, K. I. Impacts of data quantity on fisheries stock assessment. Aquat. Sci. 65, 92-98 (2003).

48. Otway, N. \& Craig, J. R. Effects of hook size on the catches of undersized snapper Pagrus auratus. Mar. Ecol. Prog. Ser. 93, 9-15 (1993).

49. Alós, J., Palmer, M., Grau, A. M. \& Deudero, S. Effects of hook size and barbless hooks on hooking injury, catch per unit effort, and fish size in a mixed-species recreational fishery in the western Mediterranean Sea. ICES J. Mar. Sci. 65, 899-905 (2008).

50. Johnson, T. R. Cooperative research and knowledge flow in the marine commons: Lessons from the Northeast United States. Int. J. Commons 4, 251-272 (2010).

51. Duda, M. D. \& Nobile, J. L. The fallacy of online surveys: No data are better than bad data. Hum. Dimens. Wildl. 15, 55-64 (2010).

52. Granek, E. F. et al. Engaging recreational fishers in management and conservation: global case studies. Conserv. Biol. 22, 1125-34 (2008).

53. Cooke, S. J. \& Cowx, I. G. The role of recreational fishing in global fish crises. Bioscience 54, 857-859 (2004).

54. Smith, K. et al. Status of Nearshore Finfish Stocks in South-western Western Australia Part 1: Australian Herring. Fisheries Research Report No. 246194 (2013). http://www.fish.wa.gov.au/Documents/research_reports/frr246.pdf Date of access: 02/04/2014.

55. Brown, J., Dowling, C., Hesp, A., Smith, K. \& Molony, B. Status of Nearshore Finfish Stocks in South-western Western Australia. Part 3. Whiting (Sillaginidae). Fisheries research Report No. 248128 (2013). http://www.fish.wa.gov.au/ Documents/research_reports/frr248.pdf Date of access: 02/04/2014.

56. Wakefield, C. B., Newman, S. J. \& Molony, B. W. Age-based demography and reproduction of hapuku, Polyprion oxygeneios, from the south coast of Western Australia: implications for management. ICES J. Mar. Sci. 67, 1164-1174 (2010).

57. Wakefield, C. B., Newman, S. J., Marriott, R. J., Boddington, D. K. \& Fairclough, D. V. Contrasting life history characteristics of the eightbar grouper Hyporthodus octofasciatus (Pisces: Epinephelidae) over a large latitudinal range reveals spawning omission at higher latitudes. ICES J. Mar. Sci. 70, 485-497 (2013).

58. Dedual, M. et al. Communication between scientists, fishery managers and recreational fishers: lessons learned from a comparative analysis of international case studies. Fish. Manag. Ecol. 20, 234-246 (2013).

59. Fairclough, D. The Biology of Four Tuskfish Species (Choerodon: Labridae) in Western Australia (204 (2005). http://researchrepository.murdoch.edu.au/47/ Date of access: 02/04/2014.

60. Wakefield, C. B. Latitudinal and Temporal Comparisons of the Reproductive Biology and Growth of Snapper, Pagrus auratus (Sparidae), in Western Australia. 162 (2006). http://researchrepository.murdoch.edu.au/382/ Date of access: 02/04/ 2014

\section{Acknowledgments}

The authors express their gratitude to the many recreational fishers (and the commercia sector) who contributed to the monitoring and assessment of demersal fishes by donating fish skeletons and to the businesses who donated prizes and provided drop-off locations. We are grateful to the many departmental staff who assisted with field and laboratory work, organised media, promotion and production and conducted education programs. 'Send us your skeletons' is funded by the Government of Western Australia.

\section{Author contributions}

D.F. conceived the study and led the analysis and writing of the paper. J.B. and B.J.C. were major partners in the development of the Send us your skeletons program. B.M.C. and I.K. contributed to the analysis of data. All authors contributed to the construction of the paper.

\section{Additional information}

Supplementary information accompanies this paper at http://www.nature.com/ scientificreports

Competing financial interests: The authors declare no competing financial interests.

How to cite this article: Fairclough, D.V., Brown, J.I., Carlish, B.J., Crisafulli, B.M. \& Keay, I.S. Breathing life into fisheries stock assessments with citizen science. Sci. Rep. 4, 7249; DOI:10.1038/srep07249 (2014)

This work is licensed under a Creative Commons Attribution-NonCommercialNoDerivs 4.0 International License. The images or other third party material in this article are included in the article's Creative Commons license, unless indicated otherwise in the credit line; if the material is not included under the Creative Commons license, users will need to obtain permission from the license holder in order to reproduce the material. To view a copy of this license, visit http:// creativecommons.org/licenses/by-nc-nd/4.0/ 